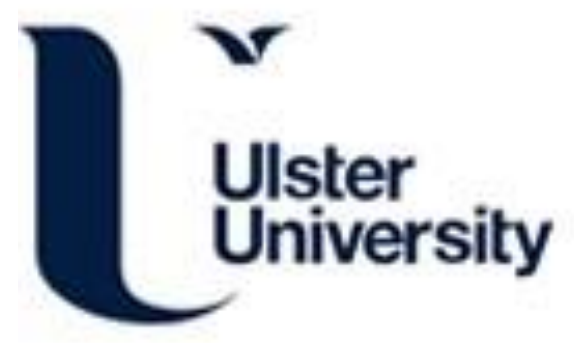

\title{
An exploratory approach for enhancing vertical and horizontal equity tests for ad valorem property tax valuations using geographically weighted regression
}

Bidanset, P., McCord, M., Davis, P., \& Sunderman, M. (2019). An exploratory approach for enhancing vertical and horizontal equity tests for ad valorem property tax valuations using geographically weighted regression. Journal of Financial Management of Property and Construction, 24(2), 231-250. https://doi.org/10.1108/JFMPC04-2019-0033

Link to publication record in Ulster University Research Portal

Published in:

Journal of Financial Management of Property and Construction

Publication Status:

Published (in print/issue): 05/08/2019

DOI:

10.1108/JFMPC-04-2019-0033

\section{Document Version}

Author Accepted version

\section{General rights}

Copyright for the publications made accessible via Ulster University's Research Portal is retained by the author(s) and / or other copyright owners and it is a condition of accessing these publications that users recognise and abide by the legal requirements associated with these rights.

\section{Take down policy}

The Research Portal is Ulster University's institutional repository that provides access to Ulster's research outputs. Every effort has been made to ensure that content in the Research Portal does not infringe any person's rights, or applicable UK laws. If you discover content in the Research Portal that you believe breaches copyright or violates any law, please contact pure-support@ulster.ac.uk. 


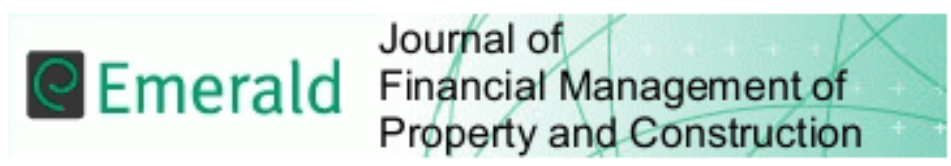

An exploratory approach for enhancing vertical and horizontal equity tests for ad valorem property tax valuations using Geographically Weighted Regression.

\begin{tabular}{|r|l|}
\hline Journal: & Journal of Financial Management of Property and Construction \\
\hline Manuscript ID & Draft \\
\hline Manuscript Type: & Research Paper \\
\hline Keywords: & $\begin{array}{l}\text { Property Taxation, Vertical Inequity, Geographically Weighted } \\
\text { Regression, Progressivity, Regressivity }\end{array}$ \\
\hline \multicolumn{2}{|l}{} \\
\end{tabular}




\title{
An exploratory approach for enhancing vertical and horizontal equity tests for ad valorem property tax valuations using Geographically Weighted Regression.
}

\begin{abstract}
Purpose: Property taxation is a crucial source of finance for local government around the world - based on a presumptive tax base underpinned by estimates of property value, Inaccurate real estate valuations used for such ad valorem or value-based property tax calculations potentially lead to a variety of costs, both financial and other, for tax payers and governments alike. More common are increased costs in time, staff, and, in some cases, legal fees. Some governments are even bound by acceptability thresholds to promote fairness, equitability and overall government accountability with respect to valuation.

Design/methodology/approach: There exist a number of vertical inequity measurements that have undergone academic testing and scrutiny within the property tax industry since the 1970's. Whilst these approaches have proved successful in detecting horizontal and vertical inequity, one recurring disadvantage pertains to measurement error / omitted variable bias, stemming largely from a failure to accurately account for location. A natural progression within property tax research is the application of a more spatially local weighted modelling approach to examine vertical and horizontal inequity. This research therefore specifies a GWR methodology to detect and measure vertical inequity in property valuations.

Findings: The findings show the efficacy of using more applied spatial approaches for vertical tax estimation and indeed the limitations of employing conditional mean estimates coupled with delineated boundaries for assessing property tax inequity. The GWR model findings highlight the more fluctuating nature of vertical inequity across the Belfast market for the apartment sector both in a progressive and regressive sense and at different magnitudes. Moreover, the results reveal spatial clustering in the effects and are indicative of systematic inequities related to location inferring that spatial (horizontal) tax inequities are not random. The findings further show increased GWR model predictability overall.

Originality/Value: This research adds to the existing literature base for evaluating both vertical and horizontal inequity in value-based property taxation at the intra-neighbourhood level. This is accomplished by modifying the Birch Sunderman approach through transforming the traditional OLS model architecture to a GWR model, thereby allowing coefficient estimates of inequity to not only vary across a jurisdiction, but at a more local level, in addition to incorporating property characteristic variables. This arguably allows assessors to identify specific geographical areas of concern, saving them money, time, and resources on identifying, addressing and correcting for inequity.
\end{abstract}

Keywords: Property taxation, Vertical inequity, GWR, Regressivity, Progressivity.

\section{Introduction}

Property tax has long been a core revenue source and one of the largest forms of tax revenue for local governments to fund their mandated expenditures on local service provision (Sokolow, 2000; Bruce, 2000; Smith, 2008). Ad valorem property taxes have a presumptive tax base, underpinned by estimates of property value which must be viewed as both fair and equitable to have broad legitimacy and acceptance. Procedures related to the calculation of, or testing for property tax equity, are therefore not only of interest to local tax assessors and 
tax lawyers but homeowners, real estate professionals and taxpayers (Birch and Sunderman, 2013). The debate around property tax has often focused on why fair and equitable property tax is needed or the reasons for (under)collection rates for generating municipal revenues, primarily within decentralized administrations. An efficient property tax not only results in tax regimes which are effective in generating revenue whilst lowering administrative costs, but also increases government transparency and accountability. Specialists in public finance see advantages to a property tax because it provides fiscal and political autonomy for local governments (Slemrod, 1995). In terms of this autonomy, in theory, property tax provides the potential for increased economic efficiency, as it establishes a 'tax price' that taxpayers can react to and challenge accordingly, which is direct and visible and creates political accountability (Oates, 1996).

Despite this, the efficiency of property as a tax mechanism is continuously scrutinized. As Johns and Wutthicharoen (2002) contend, if administrated correctly it can provide incentives for efficient land use and promote public policy, however, if not administered properly, any tax advantage can be lost, and it can distort land use and create excess burdens, especially for mobile capital. A core challenge for the efficiency and administration of property tax centre on the consistency and accuracy of the measurement of an annual taxable value - primarily as a result of limited market transaction evidence which hampers accuracy and consistency in the valuations which form the tax base, raising concerns regarding questions regarding uniformity and equity.

Whilst there has been a relatively rich history examining and estimating property tax, it is generally considered problematic in terms of regressivity, administratively flawed and influenced by externalities - culminating in vertical and horizontal inequities (Fisher, 1996). Consequently, academic debate has focused on issues such as the level of the property tax, administration and assessment procedures, the regressive or progressive nature of the tax and the equity of the tax both vertically and horizontally (Benson and Schwartz, 1997). Indeed, questions of uniformity and equity in the property tax arena remain pervasive (Smith, 2008). Dynamic housing markets and geographic unevenness of price inflation continues to present assessment challenges.

The general benchmark basis for tax assessment equity pertains to the assessment to sales ratio which associates (open) market value and predicted value. Vertical inequity manifests when properties with different market values pay a different proportionate share of property taxes relative to their market values, thus the ratio of assessed value to market value is not constant across different value ranges. The culmination is an unequal tax burden between higher-value and lower-value properties in the same property group, which manifests in either progressive or regressive taxation. Moreover, horizontal equity - a public finance concept of equal treatment of equals (Atkinson and Stiglitz 1980) denotes that properties with similar market value are treated uniformly and appraised at the same percentage of market value (IAAO 1978), or that ratios are approximately similar, regardless of stratum (e.g. property types, age, architectural styles, locations). As Sirmans et al. (1996) point out, horizontal inequity occurs when 'like' properties having the same market values are assessed differently because of the following explanations, (a) from unequal knowledge of market participants, unequal negotiating skills of buyers and sellers, and actions by officials to limit property tax increases; (b) older homes being underassessed relative to newer homes, homes with views being over-assessed, and houses with larger lots being under-assessed; (c) positively related to the complexity of the jurisdiction's taxing structure; (d) Tax initiatives to limit property value; (e) models measuring vertical inequity generally examine the relationship between assessed value and market value. 
There has been much research which has tested for the presence of inequities in the assessment process (Sirmans et al., 1996). Early studies relied almost exclusively on the ratio of assessed value to sales price within an entire tax administrative area in order to explain the variation in property tax burdens. This issue is discussed by Birch and Sunderman (2013), who highlight that the problems associated with more primitive 'pure' district models is the lack of, or neglect of accounting for neighbourhood variation or locational effects - despite the importance of location as a dynamic in the appraisal of residential property. This aspect has generated considerable debate in the extant literature regarding the relative equity of residential property tax levels, and whether that equity is value or location based (Birch and Sunderman, 2013). Numerous studies (Smith, 2000; Smith, Birch, Sunderman, 2003; Smith, 2008; Cornia and Slade, 2005; Birch and Sunderman, 2013) have introduced neighbourhood characteristics to negate the measurement error / omitted variable bias problem, extending the regression methodology to encompass sets of dummy variables for neighbourhoods to better estimate vertical and horizontal inequity. Whilst these studies advance from the traditional methods and increase the robustness of intra-jurisdictional inequity identification, they still employ conditional mean estimates for each neighbourhood control variable used in the analysis. From a spatial econometrics perspective, the application of delineated sub-markets (neighbourhoods) merely provides conditional mean estimates for each (sub) market geography, prohibiting the varying nature of price determination whilst not complying with the assumption of constant error variance (McMillen 2010).

To address these methodological limitations, this study examines a data set of apartment transactions in the Belfast housing market. The analysis employs an expanded version of a well-established instrumental variable model as developed by Clapp (1990) and subsequently augmented by Birch \& Sunderman (2013), incorporating neighbourhood characteristics to identify whether intra-jurisdictional variation relating to the ratio of property tax to market value exists, as well as further reduce omitted variable bias with the inclusion of property characteristic variables. The approach adopted is a methodological development for neighbourhood tax inequity assessment to account for non-random spatial inequality - beyond using segmented or delineated administrative boundaries. This provides important insights into the distribution of tax burden across the Belfast market area and offers the prospect of an enhanced approach for identifying tax assessment inequity more generally, fostering more robust and reliable own source revenues for fiscally challenged jurisdictions.

\section{Literature}

\section{Vertical Inequity}

There has been a rich history of academic models developed to test for the presence of inequities in the assessment process (Sirmans et al., 1996). The literature pertaining to capitalisation of residential property taxes and tax inequity measurement is relatively long. Indeed, seminal applications date back to the 1960s and 1970s where notable research at this time was undertaken by Daicoff (1967), Netzer (1966) and Oates (1969). In an urban housing capacity Gustely (1976) scrutinised local taxes and expenditure in relation to aggregation bias for taxing owner occupied and rental dwellings and their capitalisation effects. Moreover, Wales and Wiens (1974) examined the assumption that taxes are capitalised into property value, determining that an apparent capitalisation effect is substantial and significant. Indeed, this emphasis of the economics of property tax and capitalisation laid the foundations for examining the role of inequity.

The measures used to determine vertical equity began with straightforward comparisons of the assessed value and sales price (AV/SP) ratios between properties controlling for type and 
value (Oldman and Arron, 1965). One of the original studies to investigate property tax inequity was undertaken by Paglin and Fogarty (1972), which at the time was a nuance in methodological terms regarding the incorporation of vertical and horizontal inequity. Their study examined the systematic and random bias within assessments to provide two measures of what they termed intrinsic regressivity and administrative regressivity across value ranges using value as a linear function of the observed sale price. In a similar vein, Cheng (1974) further assumes that the relationship between assessed value and sale price is nonlinear measuring the percentage changes in sale price and assessed value is required to evaluate if inequity is present. Further insights presented by the IAAO (1978) posited that the appropriate measure of vertical equity is the AV/SP ratio regressed on sales price. The basis for this approach is that the functional form allows for an intuitive explanation, namely that vertical equity exists if there is no correlation between the AV/SP ratio and sales price. The research conducted by Kochin and Parks (1982) challenged these existing approaches suggesting that these former models are biased toward regressivity due to an "errors in variables" problem as a result of sales price being used as a proxy for market value. Therefore, they proposed that logging and reversing the dependent and independent variables corrects the problem. This reverse causation, they emphasise, indicates that market value can be predicted from assessed value which they deem is inherently more accurate than sale price. Nonetheless, Bell (1984) argues that the Kochin and Parks model is flawed because it assumes market error but does not allow for subjective assessment error. Akin to Cheng (1974), Bell defends the traditional approach, but shows that nonlinear inequity is better captured by including a further quadratic term.

As discerned in the work of Kochin and Parks (1982) and Bell (1984), the primary concern with earlier approaches designed to estimate vertical inequity across single aggregations of data is the possible estimation bias primarily relating to measurement error. Ideed, a review of these methods by Sirmans, Diskin, and Friday (1995) found that most produce biased estimates as a result of measurement errors in independent variables, which produces an error in variables measurement, culminating in the standard error in variables problems and biased coefficients. Indeed, Sirmans, Diskin and Friday (1995), suggest that using sale price as a proxy for market value biases the results toward regressivity, whereas using assessed value to proxy market value results in a bias towards progressivity.

The 'measurement in errors issue' has been mainly accounted for by the introduction of the instrumental variable model as originally developed by Clapp (1990). Indeed, Clapp (1990) argues that the Bell (1984) model will be biased toward regressivity and the Kochin and Parks (1982) model will be biased toward progressivity, stating that Kochin and Parks (1982) "gives a biased estimate for vertical inequity due to measurement error in the independent variable, LnA, as LnA values are only estimates of true market values". Clapp (1990) therefore recognised that market value and assessed value are interdependent because taxes are capitalized negatively into market value. To solve the measurement issue, Clapp proposed a two-stage simultaneous equations model to measure vertical inequity based on the notion that the market value of an individual property is essentially unobservable. Specifically, he introduced an instrumental variable that accounts for the high correlation between market value and assessed value but is uncorrelated with the error terms in the Kochin and Parks model.

In a similar vein, and concomitantly, Sunderman et al. (1990) were also evaluating measurement challenges. Pertinently, the authors reveal that under particular circumstances the relationship between assessed value and sales price may be S-shaped, and therefore 
warrants dissection of the relationship in order to improve explanation. They developed a spline model breaking the regression framework into three distinct sections effectively calculating a regression line for low value properties, middle range properties and high value properties, or 'knots'. They, similar to Clapp, envisaged this to more appropriately capture any nonlinearity in the relationship between sale price and assessed value. As a result, they propose two new models to better detect and explain vertical inequity: cubic spline and piecewise spine regression. When comparing their results with the traditional vertical inequity models they find inconsistencies. In the traditional models only the Bell (1984) model detected vertical inequity whilst the Paglin and Fogarty (1972), the IAAO (1978), the Köchin and Parks (1982), and the Cheng (1974) models showed no vertical inequity. As Bell used quadratic functions, this is perhaps more tied to measuring the 'terms' of the shape of the data similar to cubic and spline methodologies. The authors detected vertical inequity in both their cubic and piecewise spline models.

Other studies have also tested the nature of various modelling approaches for considering vertical inequity. Sirmans, Diskin and Friday (1995) using Miami-Dade County sales data, provide a comparison of all the available vertical inequity models including the Clapp (1990) model and the spline regression to examine vertical equity in single-family residences. Their results are inconclusive regarding the most superlative model. Sirmans et al. do, however, suggest that the Clapp (1990) model provides the most effective alternative to the problems encountered with many of the previous models. In a similar model testing study, Benson and Schwartz (1997) examine vertical inequity in home sales in Bellingham, Washington and provide a comparison of the traditional models with the piecewise spline regression model, however reject the models that assume sales price is a function of assessed value by arguing that it is difficult to defend the notion that government officials are better at developing estimates of value than the market. Their results reveal the spline regression model to be consistent with the traditional models (Paglin and Fogarty, 1972; Cheng, 1974; Bell, 1984; and IAAO, 1978), which all models displayed regressive vertical inequity. In a later study, Smith (2000) examines home sales in Bloomington, Indiana and provides a comparison of the traditional models with the Clapp (1990) and spline models. The results showed consistency across the traditional models (Paglin and Fogarty, 1972; Cheng, 1974; Bell, 1984; and IAAO, 1978) and the Clapp model which revealed the presence of progressive vertical inequity, whereas the spline model presented more inconclusive findings.

\section{Horizontal inequity}

Early studies relied almost exclusively on the ratio of assessed value to sales price within an entire tax administrative area in order to explain the variation in property tax burdens. This issue is discussed by Birch and Sunderman (2013), who highlight that the problems associated with earlier pure district models is the lack of, or neglect of accounting for neighborhood variation, or locational effects, despite the importance of location as a dynamic in the appraisal of residential property. This, Birch and Sunderman (2013) indicate has generated numerous debate in the extant literature regarding the relative equity of residential property tax levels, and whether that equity is value or location based (Birch and Sunderman, 2013). Pertinently, this argument pertains to the systematic differences in property assessments relative to market values within or between individual neighbourhood spatial units which suggest the presence of tax inequity within and between neighborhoods in administrative districts. 
Pertinently, both Smith (2008) and Cornia and Slade (2005) highlight that inequity at the local level exists due to the presence of continuous systematic changes are occurring in the pattern of market prices within and between neighbourhoods; and the temporal lags due to the assessment adjustment process which culminate in dissimilarly in property value movements between spatial units with no corresponding property reassessments, thus creating vertical inequity within that unit. In light of this, the scholarly literature has analysed neighbourhood horizontal inequity by incorporating dummy neighbourhood variables for vertical and horizontal inequity in property tax inequity models.

An early study by Plotnick (1981) examined horizontal inequity and found a small amount of inequity using Michigan Panel Data. Borland (1990) illustrates the difficulty that assessors face by showing that the degree of inequity is positively related to the degree of complexity for the assessing jurisdiction which he measures by the number of property tax rates and the rate of change in tax rates. An early study conducted by Birch, Sunderman, and Hamilton (1992) attempted to provide some insights for undertaking more micro-based approaches to reduce inequity in a typical jurisdiction. Their results highlighted the inherent difficulty for appraisers in extracting horizontal from vertical inequity. Similarly, Goolsby (1997) examined whether there is systematic error in property assessments for owner-occupied housing in Puget Sound, Washington. The investigative analysis revealed negative coefficients for sales price indicating that higher-valued houses have lower assessment ratios in all three counties examined - confirming more local or neighbourhood inequity. Similarly, they found that older houses tend to be underassessed with both the land value ratio and variables for home size comprising positive coefficients in all counties, indicating that larger houses and houses with a larger percentage of value represented by the value of the lot are systematically over-assessed. Importantly, this study infers that assessor bias is present in all three counties in Washington State.

In a more recent study, Allen and Dare (2002) examine the complexity of horizontal inequity finding that the heterogeneity of both property and neighbourhood characteristics may affect the degree of difficulty in assessing properties - namely the variation of the assessed value around the sale price. In addition to this, Allen (2003) examines alternative methods for measuring vertical inequity in multifamily property markets using small-scale, multi-family properties. The results indicated that lower-value properties were assessed at a higher proportion of market value than higher-value properties. Smith, Sunderman, and Birch (2003) have attempted to more closely explain the causes of vertical inequity by examining the relationships between characteristics of a tax jurisdiction and the degree of vertical inequity in its assessments. In doing so, they manufactured an index of vertical inequity by county that is then predicted as a function of economic, geographic, and demographic characteristics. Their results established that a greater degree of progressive inequity is present in growing urban tax jurisdictions with high concentrations of commercial and/or industrial properties. The level of progressive inequity is also increased with the complexity in the tax jurisdiction. Following up on their 2003 study, Birch, Sunderman, and Smith (2004) test for vertical inequity using sales data for Bloomington, Indiana. Their major purpose is to compare a new model to the traditional measures of inequity. The authors use a method called Vertical Horizontal Appraisal Adjustment System (VHAAS) which they consider more robust A/S ratios and nonparametric methods, compared to measures and procedures in standard OLS. They find regressive inequity; however, emphasize that using this adjustment model the level of regressive inequity reduces.

An interesting paper in the confines of this paper is the study conducted by Cornia and Slade (2005) who analyse the uniformity of appraisal outcomes for multifamily apartment 
complexes in Phoenix, Arizona. Examining both vertical and horizontal equity over a fiveyear period, (1998-2002) they find no evidence of vertical inequity, however show modest evidence of horizontal inequity which they attribute to both complex size and geographic location which increases uniformity assessment. Importantly, they determine the presence of inequity between small and large properties, indicating that an income approach is superior to the sales comparison approach for valuing multifamily properties for tax purposes. A further study undertaken by Smith (2008) examined the intra-jurisdictional segmentation of property tax burdens on residents of Chicago, Illinois. Using a two-stage model with an instrumental variable as determined by Clapp (1990) to identify tax burden variations between neighbourhoods, Smith further specifies a second model which incorporates neighbourhood and property characteristics in an examination of variations in the ratio of property tax to market value, signalling aspects of market segmentation. Finally, Fairbanks et al. (2013) apply vertical inequity models to real estate data from Lubbock, Texas. Utilising a Monte Carlo simulation framework to more theoretically explore the performance of each inequity model, the authors generate eight different contrived inequity patterns from three different data-generating processes - manifesting in 24 stylized datasets. They therefore undertake the data-generating process which observes assessed value as a noisy function of sale prices, which reflect home values - considers the sale price as a noisy function of assessed values and considers both sale prices and assessed values to be a noisy measure of home values. Pertinently, the findings provide no clear or manifest 'best' model - nonetheless provide a methodological basis for testing vertical tax inequity in future real estate data.

The literature reveals that there remains some ambiguity as to the best approach for measuring vertical (and horizontal) inequity. Notably the literature does illustrate the interlinkages and suggests that the Clapp approach provides strong theoretical foundations for measurement which has been adopted into more nuanced analysis. Indeed, it highlights that the actual amount of omitted variable bias in previous models estimating district vertical inequity may be substantial when neighbourhood vertical and horizontal tax inequity is not accounted for. Given these concerns, earlier methodologies merely examining vertical inequity have been extended to include sets of dummy variables for neighbourhood vertical and horizontal inequity with the Birch-Sunderman arguably the best enhancement to date. The results from this study extend the academic literature on vertical inequity in property taxation by analysing jurisdictional variations in the property tax burden.

\section{Data and methods}

\section{Data}

The data is obtained from the University of Ulster House Price Index (UU HPI) over the sixth month period Q3 2015 to Q4 2015 inclusive, representing a cross-section of the Belfast Metropolitan Area (BMA) ${ }^{1}$. The data sample uses 511 achieved sales for apartments within the analysis which were initially investigated for duplicate entries, missing observations and erroneous data entry. As this paper is exploratory in nature, we only use sales for the apartment sector. An address matching exercise was performed to align the addresses for each sale transaction with their $X, Y$ coordinates using Geographical Information Software (GIS), The data was subsequently exported into the statistical package $R$ to permit geostatistical analysis. The simulated assessed value was achieved using sale price which was adjusted to its natural logarithm, the area $\left(\mathrm{m}^{2}\right)$ of the apartment dwelling and location as depicted by absolute location coordinates.

\footnotetext{
${ }^{1}$ The BMA is the largest urban area in Northern Ireland spanning $960 \mathrm{~km}^{2}$ comprising six delineated geographic District Council Areas.
} 


\section{Methods}

Natural progression within the literature and research in measuring tax inequality is to apply more spatially weighted local modelling frameworks to assess the varying nature of tax inequity across the administrative housing market structure. To examine and compare the degree of inequity in the tax assessment this research compares our model procedure against the base Clapp (1990) model and more revised Birch-Sunderman approach (2013) which accounts for neighbourhood location, in an augmented Clapp approach to uncover variations in the actual property tax burden.

\section{The Clapp Model (1990)}

The first step in the procedure is to confirm the presence of vertical property tax inequity at the jurisdictional level, and if present, determine the direction of the inequity (progressive or regressive), thus the regression methodology employed by Clapp (1990) to estimate district vertical inequity is the basis of our model. As discussed in the literature, the widely-accepted Clapp (1990) model responds to a central concern with tests of property tax inequity; with variable, assessed value or sales price, should serve as the predictor variable. The Clapp model takes the form:

$$
\operatorname{Ln} A=\alpha_{0}+\alpha_{1} Z
$$

The LnA variable is as defined above, and a 0 and a 1 are the intercept and slope parameters. 8 The instrumental variable, $Z$, is assigned the values 1,0 , and 1 , respectively, for the top, middle, and bottom one-third of all the sales properties in the analysis. When equation (1) is applied, the result is a set of fitted LnA values (called LnA*). There are three of these LnA* generated values, one of which is assigned to each property in the district. Thus, high, medium, and low property values generally receive high, medium, and low LnA* values.

The second stage of the Clapp model takes the form:

$$
\operatorname{LnS}=b_{0}+b_{d} \operatorname{Ln} A
$$

where the resulting slope value obtained for $b_{d}$ gives an estimate for district vertical inequity that has been adjusted for measurement error bias. Thus, in a later comparison of vertical inequity estimates, relatively higher slope coefficients indicate less progressive (or more regressive) taxes.

\section{Birch-Sunderman Clapp Model extension (2013)}

In this second step, the goal is to confirm that variations in the property tax inequities can be identified and segmented into geographic subsets of the jurisdiction. The Clapp model is augmented to incorporate a vector of dichotomous variables representing each observation's location in one of the government delineated wards across the Belfast market. In order to extend the study to include neighbourhoods (wards), both horizontal and vertical inequity estimates need to be developed for these spatial units. First we consider neighbourhood gross and net horizontal inequity which is measured by the overall differences in typical property assessment to sales price (A-S) ratios of individual neighbourhoods. The two-stage Clapp procedure is subsequently applied separately to each of the neighbourhoods to obtain their gross vertical inequity slope estimates. This involves the inclusion of a set of standard dummy variables to the right side of the Clapp vertical inequity equation. The resulting 
regression equation generates a set of neighbourhood treatment coefficients net of the value effect caused by district vertical inequity specified as:

$$
\operatorname{LnS}=C_{0}+\sum_{j=1}^{N} c_{0 j} D_{j}+c_{d} \operatorname{Ln} A^{*}
$$

The $D_{j}(j 1,2, \ldots N)$ represent the dummy variables for each of the $\mathrm{N}$ individual neighbourhoods where the dummy variables take values of 1 for sales in their neighbourhood and 0 elsewhere. The $\mathrm{c} 0 \mathrm{j}$ coefficients measure the relative treatment of individual neighbourhoods after district value effects have been removed, and the extent of differences in these coefficients is a measure of the neighbourhood variation. The $c_{d} \operatorname{Ln} A^{*}$ coefficient is an estimate for district vertical inequity, adjusted (by the presence of the dummy variables) for neighbourhood horizontal inequity effects.

To account for the net effect, the model is firstly used, as before, to estimate a set of adjusted LnA values $\left(\mathrm{LnA}^{* *}\right)$, where there is a separate set of three such values for each of the neighbourhoods the model is applied. Unlike the estimation of neighbourhood gross vertical inequity, to estimate net vertical inequity within each neighbourhood requires a new equation. That equation requires two sets of dummy variables to obtain estimates for neighbourhood vertical inequity and to allow for the effects of neighbourhood horizontal inequity. Since it is net vertical inequity within neighbourhoods that is desired, then the equation must also include a variable for district vertical inequity. The equation can be written as:

$$
L n S=e_{0}+\sum_{j=1}^{N} c_{0 j} D_{j}+\sum_{j=1}^{N} e_{1} \operatorname{Ln} A_{j}^{* *} D_{j}+e_{d} \operatorname{Ln} A^{*}
$$

where the sets of neighbourhood dummy variables $\left(D_{j}\right.$ and $\left.L n A_{j}^{* *} D_{j}\right)$ are assigned values of 1 and $\mathrm{LnA}^{* *}$. For sales outside their neighbourhood, the two sets of variables are both assigned 0 's. The vector, $e_{0 j}$ represents the amount the individual neighbourhood intercepts differ from the overall or main intercept term, $e_{0}$. The slope vector, $e_{1 j}$, represents the set of neighbourhood net vertical inequity parameters. The parameter, $e_{d}$, attached to $\mathrm{LnA} *$ measures district vertical inequity after individual neighbourhood horizontal and vertical inequity have been allowed for by the inclusion of the two sets of dummy variables.

This process permits distinct measures of vertical and horizontal inequity coming from individual both the neighbourhood level and the vertical inequity based on purely district forces.

\section{GWR modification}

Despite the modification and enhancement to the Clapp (1990) method, The BirchSunderman (2013) model still relies on delineated boundaries and conditional mean estimates for the entire sub-location (neighbourhoods). Our modification and augmentation to the Birch-Sunderman approach is to introduce a local weighted regression (LWR) approach, namely, Geographically weighted regression which has become a mainstream spatial modelling approach within house price analysis examining spatio-temporal analyses of neighbourhood and locational determinants. Our approach here uses the hypothesis that instead of treating the $\log$ of the fitted estimate $\left(\operatorname{Ln} A^{*}\right)$ as a constant across an entire district, or a series of neighbourhoods, this will allow $L n A^{*}$ coefficients to vary over space, allowing for intra-neighborhood vertical and horizontal inequity comparison. The GWR model is represented by the following equation with the addition of the LnA parameter: 


$$
y_{i}=\beta_{0}\left(x_{i} y_{i}\right)+\sum \beta_{k}\left(x_{i}, y_{i}\right) x_{i k}+\operatorname{Ln} A^{*}+\varepsilon_{i}
$$

where: $y_{i}=i^{\text {th }}$ sale; $\beta_{0}=$ model intercept; $\beta_{k}=k^{\text {th }}$ coefficient; $x_{i k}=k^{\text {th }}$ variable for the $i^{\text {th }}$ sale $\varepsilon_{i}=$ error term of the $i^{\text {th }}$ sale; $\left(x_{i}, y_{i}\right)=\mathrm{x}, \mathrm{y}$ coordinates of the $i^{\text {th }}$ regression point

GWR therefore uses exact $(X, Y)$ location and creates a regression for each observation based on nearest neighbours (bandwidths) thus allowing coefficients to vary continuously over the study area which can be visualised and interrogated for relationship heterogeneity. This measures the inherent relationships around each regression point $i$, where each set of regression coefficients is estimated by weighted least squares. Within this study, the weighting scheme $W i$ is calculated with a kernel function based on the proximities between regression point $i$ and the $N$ data points nearby using an $n \times n$ spatial weights matrix. This determines the weight applied to each observation, assigned relative to the subject based on geographic distance:

$$
w_{i j}=\exp \left[-d_{i j} / b^{2}\right]
$$

where: $w_{i j}=$ weight applied to the $j^{\text {th }}$ property at regression point $i ; d_{i j}=$ geographical distance in kilometres between regression point $i$ and property $j ; b=$ geographical bandwidth.

The bandwidth in GWR specifies the radius of the weighting function which is either fixed, based on absolute distance, or adaptive - fluctuating, based on a predetermined number of nearest neighbours, with the optimum bandwidth determined using the Akaike Information Criterion (AIC) to retain prediction accuracy whilst ensuring model parsimony. This research uses a tri-cube adaptive kernel function and bandwidth based on 47 nearest neighbours employing a Great Circle distance metric.

\section{Findings}

According to the Clapp (1990) model, the overall data suggests a regressive vertical inequity displaying an LnA coefficient value of 1.42, with a $77 \%$ level of explanation (Table 1). This infers that higher value properties are under appraised relative to low value properties, higher variance at the top-value estimates versus sales and increased residual error. As highlighted in the literature, although this relationship is suitable for evaluating the presence of inequities over the entire tax jurisdiction, it does not allow for the extraction of variation throughout and within the Belfast market area.

\section{$<<<$ Insert Table 1 Clapp model LnA estimate $>>>$}

The modified Clapp-Birch-Sunderman (2013) approach, applying dummy variables for each of the individual neighbourhood areas (wards) to obtain their gross vertical inequity slope estimates, reveals an LnA estimate of 1.31 (Table 2). The findings continue to reveal regressive vertical inequity albeit illustrating that this has reduced from the more global district model with the model explanation also increasing to $79.32 \%$. The results suggest that the neighbourhood factors provide compelling signals of a regressive property tax when comparing between areas. 


\section{$<<<$ Insert Table 2 Modified Birch-Sunderman model coefficients $>>>$}

Whilst reducing the omitted variable bias evident in the Clapp approach, the BirchSunderman model does not exhibit the spatial variation of the vertical inequity, with neighbourhoods coefficients comprising only a conditional mean estimate which could be under representative of very regressive and very progressive values cancelling each other out. In light of this, the GWR modified approach allows vertical inequity measurements to vary within a neighborhood/assessment jurisdiction(s) providing an intra-neighbourhood tax assessment. As observed in Table 3, the GWR model shows a much more mixed and dynamic picture. The median LnA coefficient reveals a value of 1.28 reducing the regressive nature of the tax inequity. When examining the vertical inequity estimates across the quartiles and minimum and maximum statistics, the LnA estimate clearly exhibits both progressivity and regressivity. At the first quartile, the inequity remains slightly regressive (1.054), however falls to 0.833 (minimum statistic) signalling assessments which are progressive thereby indicating that when higher priced properties pay a higher proportionate amount of taxes relative to their property's market value than lower priced properties.

\section{$<<<$ Insert Table 3 GWR model coefficient $>>>$}

In addition, the findings also spatial aggregation (clustering) and spatial concentration across the Belfast market in terms of tax inequity. As demonstrated in Figure 1, the market area towards the east of the city, and a small corridor spreading from the south towards the east exhibits a more progressive inequity, whereby higher value properties are being over appraised relative to lower value properties. Moving across the market, there appears to be more regressivity evident towards the north, city centre area and the band radiating towards the south. Interestingly, the results suggest the market can be characterised into three distinct segmented markets. Importantly, the findings also imply that the dynamism clearly illustrates that to simply infer that the Belfast market has regressivity would be an oversimplification and lead to erroneous policy conclusions.

\section{$<<<$ Insert Figure 1 LnA GWR coefficient values $>>>$}

As evidenced in Figure 2, the GWR approach further increases the explanatory power of assessment inequity, with the local regression/moving window of GWR further reducing the omitted variable bias and misspecification challenges. Moreover, scrutiny of the localized $R^{2}$ statistic provides a basis for assessing model performance and where it is deficient i.e. where further omitted variable bias and model misspecification may still be present, which can aid assessors allocate resources to these areas to increase estimation accuracy. The model predictability shows some high levels of accuracy particularly in the east of the Belfast market, the north of the city and the corridor moving towards the south-west and in the west of the city. There appears to be a more varied progressive and regressive depiction in the city centre region and in a pocket towards the south and south-east. This is a very interesting finding as market knowledge confirms the areas with higher predictive accuracy to be characterized by homogeneity in terms of property age, with more heterogeneity in terms of age profile in the areas with poorer performance estimation. The accuracy levels in the model 
does however confirm that market tax inequity variation, both progressive and regressive, is evident and that this is not due to poor model performance. Moreover, it also suggests that across value ranges a 'one size fits all' tax inequity estimation does not work - arguably due to the curved nature of the pricing strata. This is undoubtedly a consequence of the spatial element - there are areas where model estimation is working well (and others where performance is poorer), thus, can more accurately account for differences as opposed to using a spatial proxy and resulting in less mis-specification and thereby improving appraisal testing.

\section{$<<<$ Insert Figure 2 GWR Model performance $\boldsymbol{R}^{2}$ estimation $>>>$}

The findings have demonstrated that horizontal inequity (location variables) allow us to extract horizontal inequity from the vertical inequity measurement ( $\mathrm{LnA})$. This naturally leads us to question whether there remains omitted variable bias for other characteristics, in addition to location, that can cause inequities. We should include physical characteristics to see where the inequities are. That is, horizontal inequity may be causing vertical inequity (e.g. higher-priced homes in one location are "under-assessed" - due to horizontal inequity from failure to capture their property attributes). It could be that properties with particular value enhancing attributes may be outdated/inaccurate, or are correlated with some other trait that are not being taken into consideration in valuations/assessments. Indeed, without omitted variables you could conclude you have vertical inequity, but you may really have both, and the horizontal inequity causes vertical inequity.

In light of the inherent issues, we further undertake exploratory analysis encompassing additional features of property characteristics to investigate the horizontal inequity aspect - in addition to location. Given this is confined to one subset of property type (apartments) we introduce the heating type coefficient, total complex size and whether there is parking available to establish the level of vertical (and horizontal) inequity (Table 4). The results from introducing the additional horizontal coefficients into the model estimation reveals increased levels of explanation for both the Birch-Sunderman and GWR approach. Pertinently, the findings reduce the LnA coefficient estimate for the Birch-Sunderman model to 1.29 thereby reducing the level of vertical inequity. Examination of the GWR model shows increased variation in the LnA estimate, revealing it to fluctuate between 0.79 to 2.26 indicating high instances of regressivity and progressivity within tax inequity. This is an important finding as it clearly exhibits that horizontal inequity may be causing vertical inequity. Indeed, the findings suggest that without these omitted variables, errors in conclusions may be inferred - namely that vertical inequity is present, however, in reality there may be both and the horizontal inequity causes vertical inequity (because of the correlation previously explained). This appears manifest when examining the coefficient estimates for the included characteristics between the models. The conditional mean estimates for the Birch-Sunderman approach show how mis-estimation could occur and the subsequent over or under assessment in inequity would be resultant.

\section{$<<<$ Insert Table 4 Birch-Sunderman and GWR estimates $>>>$}

The GWR enhancement nonetheless permits the estimation of the Area, Electric Heat, Parking and Plot size coefficients (in this instance) to also fluctuate and providing a coefficient value at each assessed property thereby providing more granular analysis of the spatial variation as to the effects of each on value. For example, for price estimation and 
subsequent tax inequity ratio assessment, the Electric Heat coefficient displays a value range from negative 0.0025 to positive 0.1875 illustrating that this comprises a differential pricing effect across the market and therefore can contribute to horizontal inequity and thus vertical inequity estimation error if not adequately allowed to spatially vary. Indeed, further examination of the property characteristics coefficients effects on contributing to tax inequity present some important insights (Table 5). The GWR inequity assessment shows the volume and estimated degree of the parameter estimates causing horizontal and vertical inequity. Indeed, the property size attribute shows circa $37 \%$ of properties to be significant contributors towards property tax inequity with the parking and plot size attributes also displaying an effect, albeit it to a lessor degree. The analysis exhibits that apartments with electric heat are not associated with inequity.

\section{$<<<$ Insert Table 5 Coefficients comprising inequity effects $>>>$}

Indeed, as depicted in Figure 3, the Area coefficient shows the plotted observations (local regressions) that comprise a statistically significant values $(t>1.99)$ which are causing tax inequity. As evidenced, the nuance in this modified GWR approach is that this provides a detailed and granular representation for assessors who can establish how many of the property attributes are associated with inequity by location - and also where these characteristics are not associated with inequity. This is vitally important for policy as assessors can see isolate the characteristics and location to enhance their taxation assessment and therefore save time and money by only concentrating on the afflicted areas. It could be that the specific characteristic is causing an inequity or it could be correlated with something that is causing an inequity (e.g. is it really the size of the lot that's causing an issue, or are big lots correlated with other things that are contributing to inequities such as parking). These can be used as a tool for assessors to undertake diagnostics and figure out where inequity is coming from so they can isolate it and reverse it.

\section{$<<<$ Insert Figure 3 Area coefficient based on statistically significant t-values}

Overall, the analysis shows that the predictive capacity of the model estimation increases with the more spatially weighted GWR approach. As established, the modified GWR approach increases the predictive accuracy by circa 10 percentage points over the traditional base model devised by Clapp (1990) (Table 5). More importantly, given the architecture of the GWR method, and for advances in tax inequity understanding and appraisal, the isolation and analysis of the spatially varying nature of both location and property characteristics which cause both vertical and horizontal inequity is needed to more accurately depict tax inequity for a more proficient assessment.

\section{$<<<$ Insert Table 6 Model overview for predictability and accuracy $>>>$.}

\section{Conclusions}

Property tax assessment remains a core source of revenue for municipal government administration, providing an essential, and stable, balance to municipal and local fiscal structures. Effective function of these taxes requires defence of the tax base, with reference to fairness and equity. The exploratory analysis used in this paper to test the methodology 
developed serves as the basis to compare and test effectiveness in estimation of inequity against extant approaches. Indeed, the modification within this paper clearly demonstrates that the application of more spatially orientated approaches helps isolate exactly which properties are causing valuation inequity so assessors can save time and money, and target geographic locales to increase explanation and reduce both the nature and extent of vertical and horizontal tax inequality.

The main purpose of this paper is to expand district vertical inequity models through the specification of a geographically weighted regression approach. This extension to previously adjusted neighbourhood models arguably demonstrates the usefulness and significance of using such an approach to measure both vertical and horizontal inequity. Whilst previous models demonstrated the value of accounting for geographic changes and omitted variable bias when estimating district vertical inequity relative to pure district models, they too are also prone to misspecification error. In a 'true' spatial sense, these approaches only culminate in conditional mean estimates per neighborhood area contained within a district and therefore can cancel out both regressive and progressive tax inequity in an intra-neighbourhood assessment. Moreover, the application of locational dummy variables neglect to account for the varying nature of house prices, and spatial heterogeneity and therefore do not fully satisfy the assumption of constant error variance needed for robust model estimation.

In terms of the findings, the Clapp model showed there to be quite a regressive tax inequity for the apartment sector in the Belfast housing market area. The extended model employing the Birch-Sunderman augmentation of Clapp, improved the LnA estimate for the Belfast district's vertical inequity illustrating that both horizontal and vertical inequity are present. Our spatial enhancement, and the importance of the findings clearly indicate that more accurately controlling for location improves the 'location' estimates - improving vertical inequity assessment by illustrating intra-neighbourhood submarkets where there are pockets of both progressivity and regressivity. Indeed, the significance of the GWR approach is that through isolation of exact location any adjustment of neighborhood and district related assessment practices that underlie these tax inequities can be targeted and addressed, thereby further improving tax equity when used as a part of any general reassessment process.

Indeed, the results suggest that there are significant differences in property tax burdens across the spectrum of property and neighborhood characteristics, indicating systematic inequities exist in the tax burden, and the inequities exhibit an observable spatial pattern with specific characteristics of the neighborhood linked to the level of inequity. The findings further support the hypothesis that the spatial inequities are not random, but instead are related to the characteristics of the neighborhood which the GWR model has defined based on tax inequity. As a consequence, an interesting finding which emerged is the apparent spatial clustering and segmentation of tax inequality in geographic locales across the Belfast market. Whilst not surprising given the nature and structure of housing markets, the analysis illustrates manifest differences in property tax burdens and tax capitalisation impacts on fairness and uniformity for both lower and higher (poorer, wealthier) housing.

The nuance in the methodological approach developed in this paper has a number of significant practical implications for industry. In terms of policy and practice, the testing of horizontal inequity illustrated that there may be correlation effects based on the characteristics which can introduce measurement error for appraisers, preventing them from valuing uniformly. The adoption of the locally weighted approach helps isolate exactly which properties are causing valuation inequity so assessors can save time and money addressing them. Also, using GWR which allows coefficients to vary over space does not assume that these new variables are impacting equity to the same degree and magnitude. The 
methodological enhancement offered is arguably the first study (of which we are aware) which clearly provides a more granular depiction of tax inequity using absolute geographical location. The advantages of incorporating this approach into tax assessment is clearly evident as it helps appraisers isolate attributes contributing to horizonal inequity and offers insights as to whether this horizontal inequity may be causing vertical inequity. In addition, it offers a relatively adoptable and feasible method to identify intra-neighborhood and crossneighborhood inequity that spans existing aggregation borders - arguably allowing for a more informed depiction of a spatially referenced vertical inequity tax allocation. The evidence is equally important to analysts concerned with market segmentation and the implications of property tax variations on real estate markets.

A limitation to the research is that this has only examined the apartment sector and the findings remain restricted to a relatively homogeneous property type. Nonetheless, whilst the findings are restricted to one housing sector, the results show there to be quite wide variation in the LnA estimates which suggests that approaches which employ geographically delineated government/administrative boundaries do not reflect adequately the truer scale of tax inequity across markets and administrative districts. Moving forward, further research should perhaps investigate and account more for the heterogeneity of the wider property stock. The introduction of more property attributes and market based features would increase understanding of the horizontal nature of the inequity assessment and further enhance model specification and performance. In saying that, from a mass appraisal sense, the findings support the application of this novel technique for jurisdiction wide inequity assessment.

\section{References}

Advisory Commission on Intergovernmental Relations, Tax and Expenditure Limits on Local Governments, United States Advisory Commission on Intergovernmental Relations, Washington, D.C., 1995.

Atkinson, A. B. and Stiglitz, J.E. "Lectures on Public Economics," McGraw-Hill, New York (1980).

Allen, M., Measuring Vertical Property Tax Inequity in Multifamily Property Markets, Journal of Real Estate Research, 2003, 25:2, 171-84.

Allen, M., T. Springer and N. Waller, Implicit Pricing across Residential Rental Submarkets, Journal of Real Estate Finance and Economics, 1995, 11, 137-51.

Allen, M. and W. Dare, Identifying Determinants of Horizontal Property Tax Inequity: Evidence from Florida, Journal of Real Estate Research, 2002, 24:2, 153-64.

Atkinson, A. and J. Stiglitz, Lectures on Public Economics, New York, NY: McGraw-Hill, 1980.

Bahl, R. and J. Linn, Urban Public Finance in Developing Countries, Oxford: Oxford University Press, 1992.

Bell, E., Administrative Inequity and Property Assessment: The Case for the Traditional Approach, Property Tax Journal, 1984, 3:2, 123-31.

Benson, E. and A. Schwartz, Jr., Vertical Equity in the Taxation of Single-Family Homes, Journal of Real Estate Research, 1997, 14:3, 215-31.

Berndt, E., The Practice of Econometrics: Classic and Contemporary, Chapter 4, The Measurement of Quality Change: Constructing an Hedonic Price Index for Computers Using Multiple Regression Methods, Addison-Wesley Publishing Company, Inc., 1991, 102-49. 
Berry, B. and R. Bednarz, A Hedonic Model of Prices and Assessments for Single Family Homes: Does the Assessor follow the Market or the Market Follow the Assessor?, Land Economics, 1975, 51:1, 21-40.

Birch, J., M. Sunderman and T. Hamilton, Adjusting for Vertical Inequity in Property Assessment, Property Tax Journal, 1990, 9:3, 197-211. Bowman, J. and J. Mikesell, Uniform Assessment of Property: Returns from Institutional Remedies, National Tax Journal, 1978, 31:1, 137-53.

Birch, J. W., Sunderman, M. A., \& Smith, B. C. (2004). Vertical inequity in property taxation: A neighborhood based analysis. The Journal of Real Estate Finance and Economics, 29(1), 71-78.

Birch, J. and Sunderman, M. (2013). Regression modeling for vertical and horizontal property tax inequity. Journal of Housing Research, 23(1), 89-104.

Bruce, N., Public Finance and the American Economy, New York, NY: Addison-Wesley, 2000.

Brueckner J., A Modern Analysis of the Effects of Site Value Taxation, National Tax Journal, 1986, 39:1, 49-58. Cheng, P., Property Taxation, Assessment Performance and Its Measurement, Public Finance, 1974, 29:3, 268-84.

Chernick, H. and A. Reschovsky, The Taxation of the Poor, Journal of Human Resources, $1990,25: 4,712-35$.

Clapp, J., A New Test for Equitable Real Estate Tax Assessment, Journal of Real Estate Finance and Economics, 1990, 3:9, 232-49. DeCesare, and L. Ruddock, A New Approach to the Analysis of Assessment Equity, Assessment Journal, 1998, 57-69.

Cornia G. and Slade, B. (2005). Real Property Taxation Of Multifamily Housing: An Empirical Analysis Of Vertical And Horizontal Equity. The Journal of Real Estate Research, 27(1): 17- 46.

Fairbanks, J., Goebel, P., Morris, M., \& Dare, W. (2013). A Monte Carlo Exploration of the Vertical Property Tax Inequity Models: Searching for a 'Best'Model. Journal of Real Estate Literature, 21(1), 3-24.

Fisher, G., The Worst Tax: A History of the Property Tax in America, Lawrence, KA, University Press of Kansas, 1996.

Frew, J. and G. D. Jud, Estimating the Value of Apartment Buildings, Journal of Real Estate Research, 2003, 25:1, 77-86.

Goolsby, W. (1997). Assessment error in the valuation of owner-occupied housing. Journal of Real Estate Research, 13(1), 33-45.

Gloudemans, R., Mass Appraisal of Real Property, International Association of Assessing Officers, Chicago, IL, 1999. Haurin, D., An Empirical Analysis of Property Tax Equity, Property Tax Journal, 1988, 5-18.

Hyman, D., Public Finance: A Contemporary Approach to Theory and Policy, Fort Worth, TX: Dryden Press, 1998. International Association of Assessing Officers, Improving Real Property Assessment: A Reference Manual, Chicago, IL: IAAO, 1978, 121-55.

Isakson, H., Using Multiple Regression Analysis in Real Estate Appraisal, The Appraisal Journal, 2001, 69:4, 424-30.

Janssen, C. and B. So"derberg, Determining Income Multipliers for Apartment Properties, The Appraisal Journal, 2000, 68:2, 151-60.

Kay, J., Tax Policy: A Survey, The Economic Journal, 1990, 100:399, 18-75. Kochin, L. and R. Parks, Vertical Equity in Real Estate Assessment: A Fair Appraisal, Economic Inquiry, 1982, 20, 511-31.

Kochin, L. A., and Parks, R. W. (1982). Vertical equity in real estate assessment: a fair appraisal. Economic Inquiry, 20(4), 511-532. 
Kowalski, J. and P. Colwell, Markets Versus Assessed Values of Industrial Land, Journal of the American Real Estate and Urban Economics Association, 1986, 14:2, 361-73.

Krupa, O. (2014). Housing Crisis and Vertical Equity of the Property Tax in a Market Valuebased Assessment System. Public Finance Review, 42(5), 555-581.

Krueckeberg, D., The Grapes of Rent: A History of Renting in A County of Owners, Housing Policy Debate, 1999, 10:1, 9-30.

McLure C. Jr., The Nuttiness of State and Local Taxes - and the Nuttiness of Responses Thereto, State Tax Notes, 2002, 25:12, 841-56.

Mehta, S. and J. Giertz, Measuring the Performance of the Property Tax Process, National Tax Journal, 1996, 49:1, 73-85.

Michaels, R. and V. Smith, Market Segmentation and Valuing Amenities with Hedonic Models: The Case of Hazardous Waste Sites, Journal of Urban Economics, 1990, 28, $223-42$.

Mills, E., Urban Economics, Second edition, Glenview, IL: Scott, Foresman and Company, 1980.

Mills, E. and L. Lubuele, Inner Cities, Journal of Economic Literature, 1997, 35:2, 727- 56. Musgrave, R., Horizontal Equity, Once More, National Tax Journal, 1990, 43:2, 11322.

Netzer, D., Economics of the Property Tax, Washington, DC: The Brookings Institution, 1966. Oates, W., Taxation in a Federal System: The Tax Assignment Problem, Public Economics Review, 1996, 1:1, 35-60.

Oates, W. E. (1996). Taxation in a federal system: the tax-assignment problem. University of Maryland, Department of Economics.

Oldman, O. and H. Aaron, Assessment-Sales Ratios Under the Boston Property Tax, National Tax Journal, 1965, 18:1, 36-49. Palmon, O. and B. Smith, New Evidence on Property Tax Capitalization, Journal of Political Economy, 1998, 106:5, 1099-1111.

Paglin, M. and M. Fogarty, Equity and the Property Tax: A New Conceptual Focus, National Tax Journal, 1972, 25:4, 557-65.

Pearson, T., Assessment Ratios and Property Tax Burdens in Norfolk, Virginia, 1974-75, Journal of the American Real Estate and Urban Economics Association, 1979, 7:X, $190-203$.

Schnare, A. The Impact of Changes in Multifamily Housing Finance on Older Urban Areas, The Bookings Institution, Center on Urban Metropolitan Policy and The Harvard Joint Center for Housing Studies, Cambridge, MA, 2001.

Segal, L. and D. Sullivan, Trends in Homeownership: Race, Demographics, and Income, Economic Perspective, Federal Reserve Bank of Chicago, 1998, (Second Quarter), $53-72$.

Sirmans, G., B. Diskin and H. Friday, Vertical Inequity in the Taxation of Real Property, National Tax Journal, 1995, 49, 71-84. Slade, B., Office Rent Determinants During Market Decline and Recovery. Journal of Real Estate Research, 2000, 20:3, 357-80.

Sirmans, S., Gatzlaff, D., \& Macpherson, D. (2008). Horizontal and vertical inequity in real property taxation. Journal of Real Estate Literature, 16(2), 167-180.

Slemrod, J., Professional Opinions About Tax Policy: 1934-1994, National Tax Journal, 1995, 48, 121-47. Smith, B., Applying Models for Vertical Inequity in the Property Tax in a Non-Market Value State, Journal of Real Estate Research, 2000, 19:3, 32144.

Smith, C. and A. Islam, Apartment Rents-Is There a "Complex' Effect?,' The Appraisal Journal, 1998, 263-68. 
Smith, B. C., Sunderman, M. A., \& Birch, J. W. (2003). Sources of variation in county property tax inequities. Journal of Public Budgeting, Accounting \& Financial Management, 15(4), 571.

Smith, B. (2000). Applying models for vertical inequity in the property tax to a non-market value state. Journal of Real Estate Research, 19(3), 321-344.

Smith, B. (2008). Intrajurisdictional segmentation of property tax burdens: Neighborhood inequities across an urban sphere. Journal of Real Estate Research, 30(2), 207-224.

Sokolow, A. D. (2000). The changing property tax in the West: State centralization of local finances. Public Budgeting \& Finance, 20(1), 85-104.

Sunderman, M., J. Birch, R. Cannaday and T. Hamilton, Testing for Vertical Inequity in Property Tax Systems, Journal of Real Estate Research, 1990, 5:3, 319-34.

Tiao, G. and A. Goldberger, Testing Equality of Individual Regression Coefficients, WEBH Paper 6201, University of Wisconsin, Social Systems Research Institute, Madison, Wisconsin, 1962.

Tideman, N., E. Akobundo, A. Johns, and P. Wutthicharoen, The Avoidable Excess Burden of Broad-Based U.S. Taxes, Public Finance Review, 2002, 30:3, 416-41.

U.S. Census Bureau, Housing Characteristics: 2000; Census 2000 Brief, U.S. Department of Commerce, Economics and Statistics Administration, Washington, DC, 2001.

Wolverton, M., W. Hardin and P. Cheng, Disaggregation of Local Apartment Markets by Unit Type, Journal of Real Estate Finance and Economics, 1999, 19:3, 243-57.

Zodrow, G., The New View of the Property Tax: A Reformulation, Regional Science and Urban Economics, 1986, 16:3, 309-27. 
Table and figure Enhancing vertical inequity paper submission

Tables

Table 1 Clapp model LnA estimate

\begin{tabular}{llll}
\hline & $\mathrm{B}$ & Std. Error & $\mathrm{t}$ value \\
\hline Intercept & -4.9039 & 0.3977 & $-12.330^{* * *}$ \\
LnA & 1.4210 & 0.0343 & $41.411^{* * *}$ \\
$R^{2}$ & 0.7711 & & \\
Adj. $R^{2}$ & 0.7707 & & \\
$F$-stat & $1715.0^{* * *}$ & & \\
$N$ & 511 & & \\
$* * * *$ denotes statistical significance at the $1 \%$ level; $* * 5 \%$ level; $* 10 \%$ level
\end{tabular}

Table 2 Modified Birch-Sunderman model coefficients

\begin{tabular}{llll}
\hline & $\mathrm{B}$ & Std. Error & $\mathrm{t}$ value \\
\hline Intercept & -3.7276 & 0.4341 & $-8.586^{* * *}$ \\
LnA & 1.3145 & 0.0378 & $34.770^{* * *}$ \\
Ward9 & 0.0847 & 0.0365 & $2.318^{*}$ \\
Ward12 & 0.1003 & 0.0312 & $3.207^{* *}$ \\
Ward15 & 0.0307 & 0.0382 & 0.805 \\
Ward29 & 0.0545 & 0.0258 & $2.115^{*}$ \\
Ward33 & 0.0535 & 0.0360 & 1.487 \\
Ward36 & 0.0269 & 0.0350 & 0.768 \\
Ward37 & 0.0337 & 0.0433 & 0.778 \\
Ward38 & 0.0566 & 0.0230 & $2.459^{*}$ \\
Ward42 & 0.1991 & 0.0260 & $7.640^{* * *}$ \\
Ward49 & 0.0688 & 0.0349 & $1.970^{*}$ \\
$R^{2}$ & 0.7976 & & \\
$A d j . R^{2}$ & 0.7932 & & \\
$F$-stat & $178.8^{* * *}$ & \multicolumn{2}{l}{} \\
$N$ & 511 & \\
***denotes statistical significance at the $0.1 \%$ level; $* * 1 \%$ level; $* 5 \%$ level
\end{tabular}

Table 3 GWR model coefficient

\begin{tabular}{llllll}
\hline & Min & $1^{\text {st }} \mathrm{Qu}$. & Median & $3^{\text {rd }} \mathrm{Qu}$. & $\mathrm{Max}$ \\
\hline Intercept & -15.1393 & -5.2677 & -3.3325 & -0.6751 & 1.9390 \\
LnA & 0.8333 & 1.0536 & 1.2852 & 1.4510 & 2.3080 \\
R2 & 0.8554 & & & & \\
Adj. R2 & 0.8369 & & & & \\
AICc & -503.0763 & & & & \\
$\mathrm{~N}$ & 511 & & & & \\
\hline
\end{tabular}

Kernel function: tricude. Adaptive bandwidth: 47 (nearest neighbours). Great Circle distance metric employed. 
Table 4 Birch-Sunderman and GWR estimates

\begin{tabular}{|c|c|c|c|c|c|c|c|}
\hline & \multicolumn{2}{|c|}{ Birch-Sunderman } & \multicolumn{5}{|c|}{ GWR } \\
\hline & $\beta$ & t value & Min & $1^{\text {st }} \mathrm{Q}$ & Median & $3^{\text {rd }} \mathrm{Q}$ & Max \\
\hline Intercept & -3.4913 & & -0.014779 & -0.2210 & -0.1043 & -0.3704 & 2.835 \\
\hline LnA & 1.2920 & $34.770 * * *$ & 0.79044 & 0.9510 & 1.0562 & 1.1790 & 2.256 \\
\hline Ward9 & 0.08477 & $2.318^{* *}$ & & & & & \\
\hline Ward12 & 0.10037 & $3.207 * *$ & & & & & \\
\hline Ward15 & 0.03075 & 0.805 & & & & & \\
\hline Ward29 & 0.05459 & $2.115^{* *}$ & & & & & \\
\hline Ward33 & 0.05335 & 1.487 & & & & & \\
\hline Ward36 & 0.02693 & 0.768 & & & & & \\
\hline Ward37 & 0.03374 & 0.778 & & & & & \\
\hline Ward38 & 0.05669 & $2.459 * *$ & & & & & \\
\hline Ward42 & 0.19916 & $7.640 * * *$ & & & & & \\
\hline Ward49 & 0.06882 & $1.970 *$ & & & & & \\
\hline Area & 0.003455 & $7.968 * * *$ & 0.000891 & 0.00212 & 0.00280 & 0.004207 & 0.00820 \\
\hline Plot size & 0.000262 & 0.170 & 0.02277 & 0.00074 & 0.00026 & 0.02062 & 0.0329 \\
\hline Parking & 0.00416 & 1.553 & -0.0413 & -0.0107 & -0.0051 & 0.00540 & 0.3831 \\
\hline Electric Heat & -0.0040 & $1.981 * *$ & -0.02543 & -0.0079 & -0.0032 & 0.0540 & 0.1875 \\
\hline$R^{2}$ & 0.8311 & & 0.8951 & & & & \\
\hline $\operatorname{Adj} . R^{2}$ & 0.8260 & & 0.8692 & & & & \\
\hline$F$-stat & $162.4 * * *$ & & & & & & \\
\hline$A I C^{a}$ & & & $-689.118^{a}$ & & & & \\
\hline$N$ & 511 & & 511 & & & & \\
\hline
\end{tabular}

Table 5 Coefficients comprising inequity effects $>>>$

\begin{tabular}{lcc}
\hline Property Characteristic & Significant Obs. & \% Obs. \\
\hline Plot size & 66 & 12.91 \\
Electric heat & 2 & 0.004 \\
Area & 190 & 37.18 \\
Parking & 37 & 7.24 \\
\hline Significant Obs. $(t>1.99, p<.05)$ & &
\end{tabular}

Table 6 Model overview for predictability and accuracy

\begin{tabular}{lcc}
\hline Model type & Adj. $\mathbf{R}^{\mathbf{2}}$ & Accuracy \\
\hline Clapp: & 77 & Base model \\
Modified Clapp (Birch Sunderman): & 79 & +2 \\
Modified GWR: & 84 & +7 \\
Modified Clapp (BS) with property characteristics: & 83 & +6 \\
Modified GWR with property characteristics: & 87 & +10 \\
\hline
\end{tabular}




\section{Figures}

\section{Figure 1 LnA GWR coefficient values}

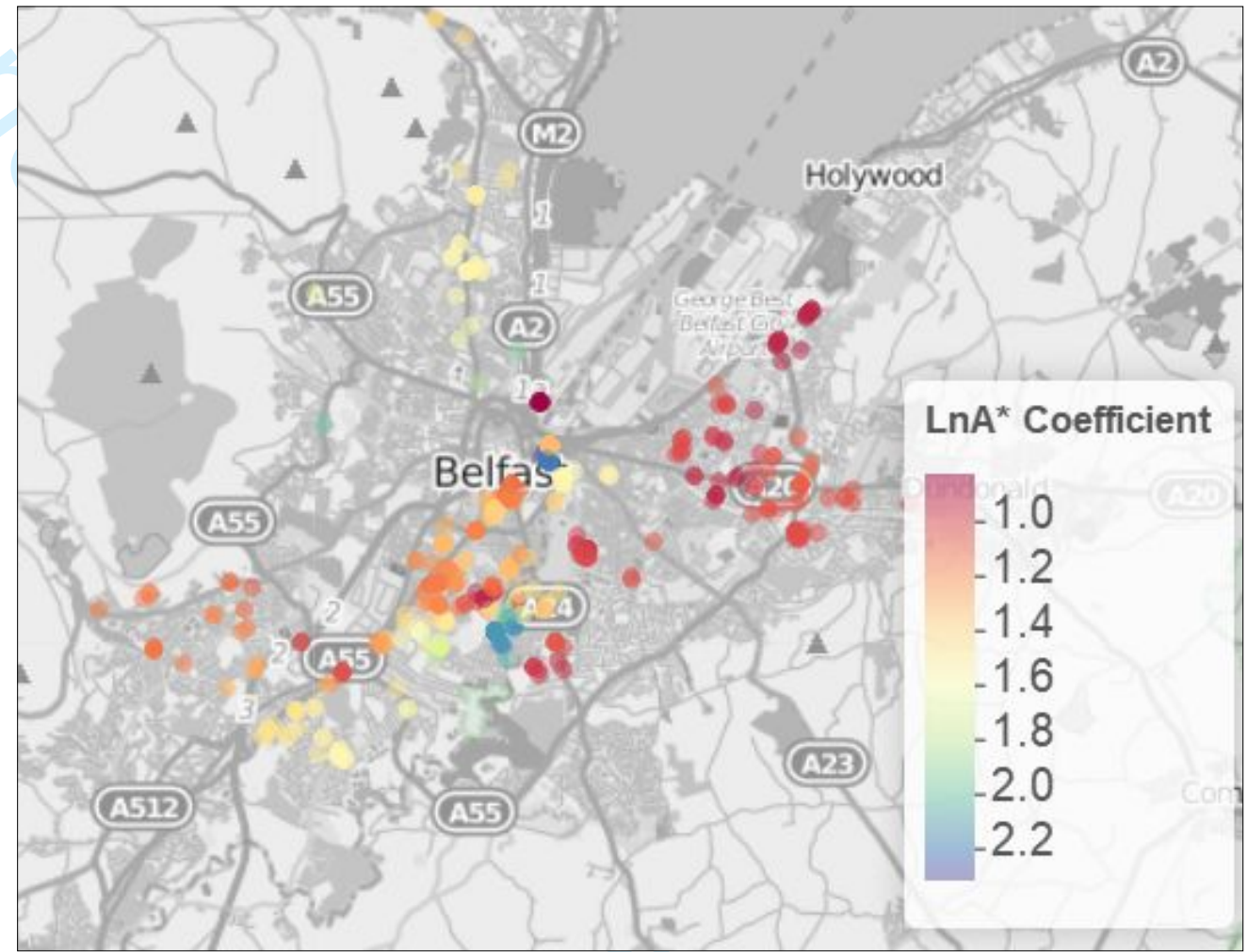

Figure 2 GWR Model performance $R^{2}$ estimation

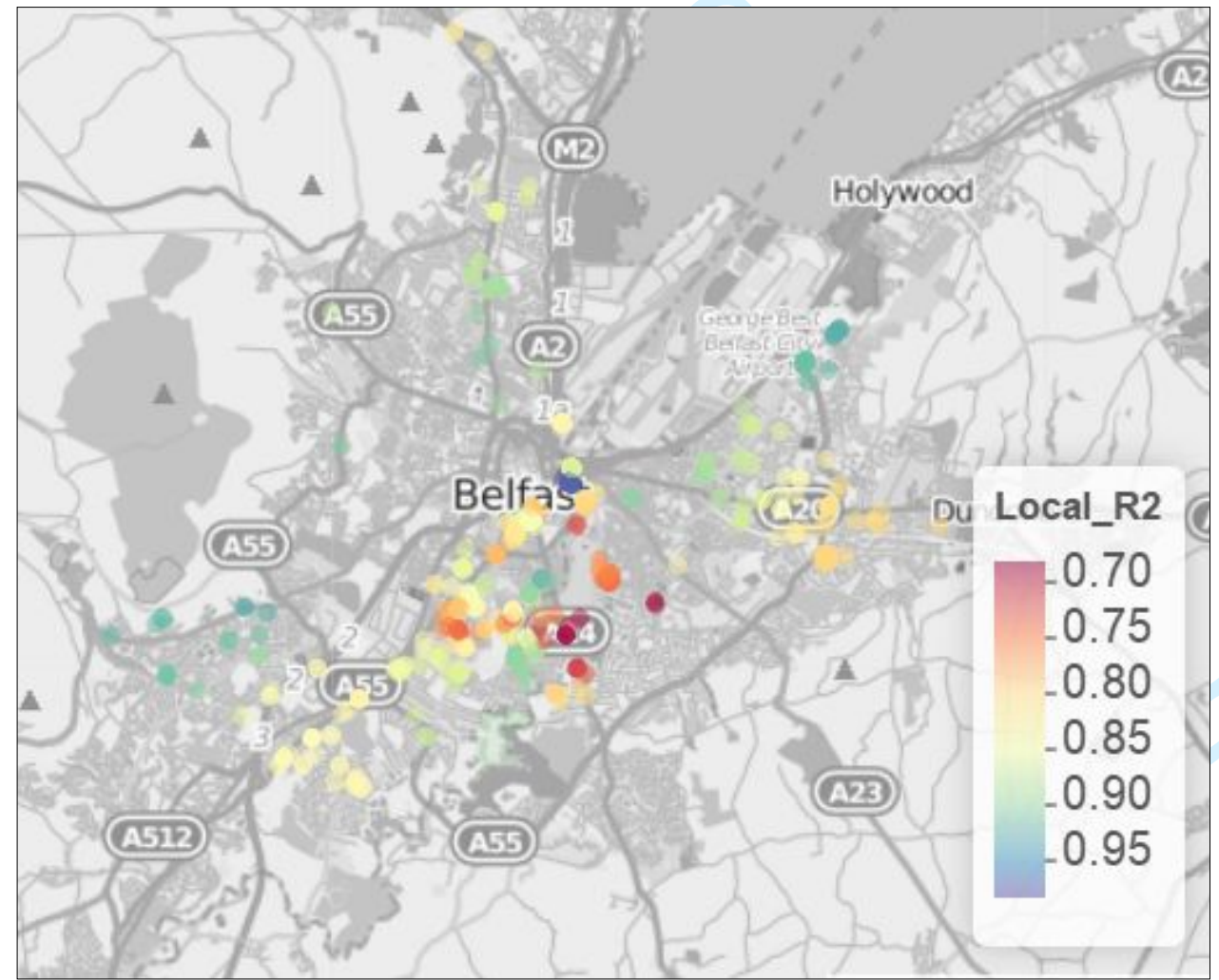


Figure 3 Area coefficient based on statistically significant t-values

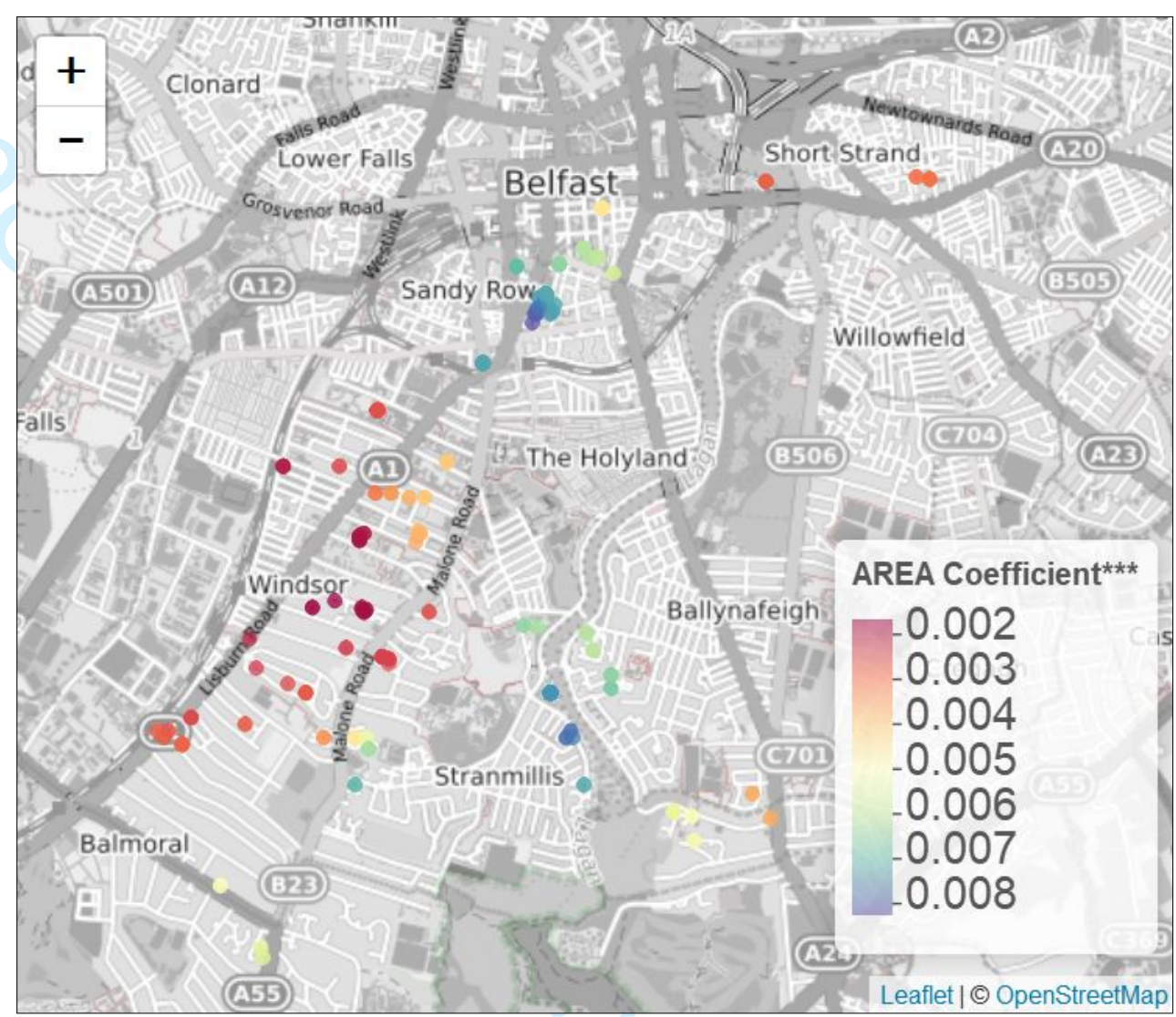

